\title{
Coracoid Process Morphology using 3D-CT Imaging in a Malaysian Population
}

\author{
Imma II, MS Orth, Nizlan NM, MS Orth, Ezamin AR, MMed Rad, Yusoff S, MS Orth, \\ Shukur MH*, MS Orth \\ Department of Orthopaedics, Universiti Putra Malaysia, Serdang, Malaysia \\ *Department of Orthopaedics and Traumatology, Universiti Kebangsaan Malaysia, Cheras, Malaysia \\ This is an open-access article distributed under the terms of the Creative Commons Attribution License, which permits unrestricted use, \\ distribution, and reproduction in any medium, provided the original work is properly cited \\ Date of submission: 19 April 2016 \\ Date of acceptance: 28 May 2017
}

\begin{abstract}
Introduction: The aims of this study are to define the coracoid process anatomy in a Malaysian population, carried out on patients in Hospital Serdang with specific emphasis on the dimension of the base of coracoid process which is important in coraco-acromial (CC) ligament reconstruction, to define the average amount of bone available for use in coracoid transfer, and to compare the size of coracoid process based on gender and race, and with findings in previous studies.

Materials and Methods: Fifteen pairs of computed tomography (CT) based 3-dimensional models of shoulders of patients aged between 20 to 60 years old were examined. The mean dimensions of coracoid were measured and compared with regards to gender and race. The data were also compared to previously published studies.

Results: The mean length of the coracoid process was 37.94 $\pm 4.30 \mathrm{~mm}$. Male subjects were found to have larger-sized coracoids in all dimensions as compared to female subjects. The mean tip of coracoid dimension overall was $19.99+$ $1.93 \mathrm{~mm}$ length $\mathrm{x} 10.03+1.48 \mathrm{~mm}$ height $\times 11.63+2.12 \mathrm{~mm}$ width. The mean base of coracoid dimension was $18.96+$ $3.71 \mathrm{~mm}$ length $\mathrm{x} 13.84+1.76 \mathrm{~mm}$ width. No significant differences were observed with regards to racial denomination. The overall coracoid size measurements were found to be smaller compared to previous studies done on the Western population.

Conclusion: This study may suggest that Malaysians have smaller coracoid dimension compared to Caucasians. The findings further suggest that the incidence of coracoid fracture and implants pull out in Malaysian subjects may be higher.
\end{abstract}

Key Words: coracoid process, coracoid anatomy, coracoid dimension, Malaysian population

\section{INTRODUCTION}

The coracoid process is significant as a bony landmark in many surgical procedures around the shoulder joint. The coracoid is used by surgeons for graft in coracoid transfer procedure for shoulder instability and also for coracoacromial (CC) ligament reconstruction procedures ${ }^{1-3}$. The anatomical dimension of coracoid therefore is crucial as the size will determine how much of the coracoid process can be harvested as a graft during coracoid transfer procedures. In $\mathrm{CC}$ ligament reconstruction, inappropriate size of drill, size of implants and even the inaccurate trajectory of tunnel drilling can increase the risk of coracoid fracture and implant pull-out. By having our own data for the population in this region, it may provide information to surgeons on how much cortical wall remains during tunnel preparation in $\mathrm{CC}$ ligaments reconstruction.

Various studies have been carried out on coracoid morphology using dry bone, fresh cadaveric bone and computed tomography. However, most do not provide comprehensive reports of the entire coracoid anatomical dimensions. Instead, the coracoid process was studied partly following the procedure they were discussing. For example, the entire length of coracoid process and its tip were measured for coracoid transfer procedure for gleno-humeral instability and its base was most discussed in CC reconstruction surgery. There are no studies done in Malaysia thusfar and only limited literatures are available that defines the anatomical dimension of coracoid process using $\mathrm{CT}$ scan $3 \mathrm{D}$ reconstruction.

As Asian individuals are smaller in physical size compared to Caucasians, using surgical devices and implants that are designed for the Caucasians will impose inappropriate risks of intra-operative and post-operative coracoid fractures and implant pull-outs. Therefore, the primary aim of this study is

Corresponding Author: Mohd Nizlan Mohd Nasir, Department of Orthopaedics, Universiti Putra Malaysia, Serdang, Malaysia Email: neezlan@yahoo.com 
to define the entire coracoid anatomy and its measurement in our population by using $\mathrm{CT}$ scan $3 \mathrm{D}$ reconstruction and comparing its value to other previous studies. It is our hope that this data will be useful in the future to provide a cause for the incidence of coracoid fractures and implant failures with the usage of implants of sizes currently available in the market.

\section{MATERIALS AND METHODS}

This is a descriptive and prospective study. Fifteen patients were included in this study, involving 15 pairs of shoulder joints. The range of the age was between 20 to 60 years. The procedure was performed in the Radiology Department, Hospital Serdang, Malaysia. All patients who were selected in this study were those with lung pathology that required CT scan of the thorax for diagnosis. Exclusion criteria were history of fracture involving the clavicle and coracoid process, arthritis around the shoulder joint, tumours around the shoulder and gleno-humeral and acromioclavicular joint instability

All CT scans were performed on a 128/DE CT Scanner (Somatom Sensation Flash, Siemens Medical Solution manufactured in Erlangen, Germany). The scan covered an area from the upper thorax to the adrenal glands in craniocaudal orientation. The scanning protocol with a pitch of 1.0 acquisition of $(128 \times 2) \times 0.6 \mathrm{~mm}$ (z-flying focus spot) and rotation time of 0.28 seconds was used with Tube A- $80 \mathrm{kV}$ at $382 \mathrm{mAs}$ and Tube B-140 kV at $90 \mathrm{mAs}$. Automated tube current modulation (CareDose 4D, Siemens Medical Solution) was applied in this protocol. Images were reconstructed at a $0.75 \mathrm{~mm}$ slice thickness in MPR and maximum-intensity-projection images and volume rendering. Image analyses were done using syngo.via (Siemens Healthcare) 3D Maximum Intensity Projection (MIP) with direct body bone removal as this is more representative. Analysis using multiplanar reconstruction (MPR) and volume rendering was allowed. Images from 3D reconstructed CT scan of the shoulder joints were cropped and devoid of structures other than scapula based on study by Rios3 (Fig. 1-3). The measurement was done using an electronic calliper. This process was conducted by two different individuals at different time using the same final images. The dimension of the coracoid process was measured in millimetres (mm) as 1) total length: a 2) tip of coracoid: c x e x f and 3) base of coracoid: b x d x g and each parameter was recorded in a spread sheet.

\section{RESULTS}

Data collected were analysed using the SPSS version 19.0 software to generate descriptive and analytical statistics. This study involved 15 subjects with the majority of the cases being female (60.0\%). Ethnic Malay subjects contributed $73.3 \%$ of the cases while Chinese and Indian subjects contributed $13.3 \%$ each.

The mean total length of coracoid from tip to base in this study was $37.94+4.30 \mathrm{~mm}$. Mean coracoid length in male subjects was $40.88+3.87 \mathrm{~mm}$ while in females the coracoid length was $35.98+3.49 \mathrm{~mm}$ with average $5 \mathrm{~mm}$ difference between male and female subjects. Male subjects had significantly larger coracoid processes compared to female subjects (Table I).

The mean tip of coracoid dimension was $19.99+1.93 \mathrm{~mm}$ length $\times 10.03+1.48 \mathrm{~mm}$ height $\times 11.63+2.12 \mathrm{~mm}$ width. Meanwhile, the mean base of coracoid dimension was 18.96 $+3.71 \mathrm{~mm}$ length x $13.84+1.76 \mathrm{~mm}$ width (Table II).

It is difficult to compare the parameters used in this study with other studies as the others had their own way of measuring the portions (some did not disclose the process in detail). Some studies used cadaveric bone and some used CT scan. This mixture of studies is definitely not uniform in term of measurements. However, their definition of the parameters was close to ours. All the measurements were tabulated in Table II for comparison.

\section{DISCUSSION}

The anatomy of the coracoid process is complex (Table III). It presents a curved shape. The base of the coracoid or the inferior pillar (vertical portion of the coracoid) originates off the antero-superior aspect of the glenoid vault ${ }^{1}$. It is connected to the superior pillar (horizontal limb of the coracoid) at the coracoid 'elbow' or junction and traverses laterally and terminates at the tip of coracoid'. The coracoid assumes a biomechanical function as a lever through which the muscular action of the coracobrachialis and short head of biceps tendon (conjoint tendon) and the pectoralis minor muscles exert force on the glenoid ${ }^{4}$.

Known as the safe-zone 'lighthouse' during surgery, this tiny portion of the scapula has been used by surgeons largely to treat acromio-clavicular (AC) joint dislocation, Bankart lesion in shoulder instability and many more shoulder conditions $^{2,3,5}$. However, these surgeries may also contribute to fracture of the coracoid process and implant failure. Hence, the authors are of the opinion that the size of coracoid process is an important factor in these surgeries.

Lo et $a l^{5}$ in their cadaveric study measured the dimension of the tip of the coracoid process while evaluating the anatomic relationship of the coracoid to the neurovascular structures that are at risk of injury during arthroscopic coracoplasty. In this study, the mean dimensions of the coracoid tip were $15.9 \mathrm{~mm} \times 22.7 \mathrm{~mm} \times 10.4 \mathrm{~mm}$ (width $\times$ length $\mathrm{x}$ height). 
Table I: Measurement of coracoid process in this study

\begin{tabular}{|lc|}
\hline View & Mean \pm SD $(\mathbf{m m})$ \\
\hline Anterior view & \\
Total length & $37.94 \pm 4.30$ \\
Base length & $18.96 \pm 3.71$ \\
Lateral view & \\
Tip height & $9.24 \pm 1.16$ \\
Base height & $15.03 \pm 3.65$ \\
Superior view & \\
Tip length & $20.98 \pm 2.90$ \\
Tip width & $11.63 \pm 2.12$ \\
Midpoint width & $13.84 \pm 1.76$ \\
\hline
\end{tabular}

All values are expressed as mean \pm SD

Table II: Comparison of coracoid process according to gender

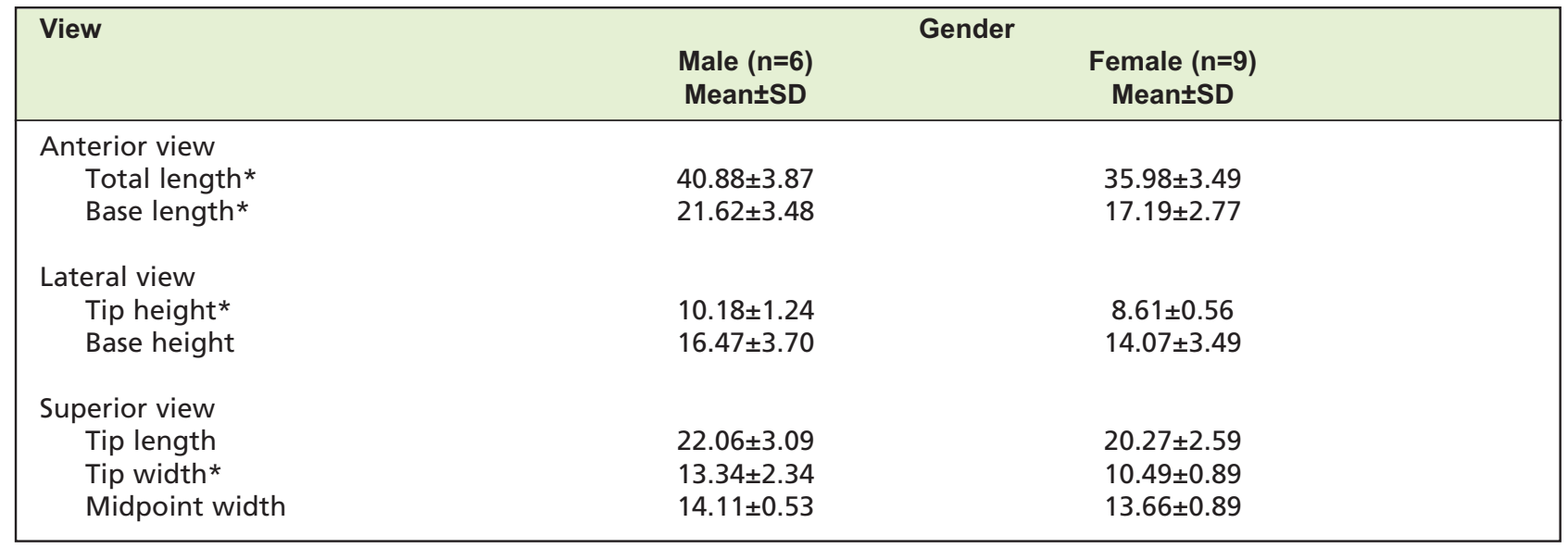

*Significant if $p$-Value $<0.05$

Table III: Previous studies on measurement of the coracoid process

\begin{tabular}{|c|c|c|c|c|c|c|}
\hline Study & & $\begin{array}{c}\text { Coracoid } \\
\text { length } \\
(\mathrm{mm})\end{array}$ & $\begin{array}{l}\text { Coracoid } \\
\text { tip width } \\
(\mathrm{mm})\end{array}$ & $\begin{array}{l}\text { Coracoid } \\
\text { tip height } \\
(\mathrm{mm})\end{array}$ & $\begin{array}{c}\text { Coracoid } \\
\text { base width } \\
(\mathrm{mm})\end{array}$ & $\begin{array}{l}\text { Coracoid } \\
\text { base height } \\
(\mathrm{mm})\end{array}$ \\
\hline Lo et al (2004) & Pooled & 22.7 & 15.9 & 10.4 & & \\
\hline Rios et al (2007) & $\begin{array}{l}\text { Pooled } \\
\text { Males } \\
\text { Females }\end{array}$ & $\begin{array}{l}45.2 \pm 4.1 \\
46.3 \pm 3.3 \\
40.7 \pm 4.3\end{array}$ & & & $\begin{array}{l}24.9 \pm 2.4 \\
25.4 \pm 2.0 \\
23.0 \pm 2.8\end{array}$ & $\begin{array}{c}11.9 \pm 1.8 \\
12.2 . \pm 1.7 \\
10.5 \pm 1.6\end{array}$ \\
\hline Salzmann et al (2010) & $\begin{array}{l}\text { Males } \\
\text { Females }\end{array}$ & $\begin{array}{l}46.0 \pm 1.9 \\
42.0 \pm 1.4\end{array}$ & & & $\begin{array}{l}16.7 \pm 2.9 \\
13.0 \pm 1.7\end{array}$ & $\begin{array}{l}15.4 \pm 1.3 \\
13.6 \pm 1.7\end{array}$ \\
\hline Dolan et al (2011) & Pooled & $45.6 \pm 4.2$ & $18.3 \pm 1.8$ & $11.5 \pm 0.9$ & & \\
\hline Armitage et al (2011) & Pooled & & 15.0 & 10.5 & & \\
\hline Coale et al (2012) & $\begin{array}{l}\text { Pooled } \\
\text { Males } \\
\text { Females }\end{array}$ & $\begin{array}{l}45.0 \pm 3.8 \\
45.7 \pm 3.7 \\
41.5 \pm 2.3\end{array}$ & & & $27.9 \pm 2.5$ & \\
\hline
\end{tabular}



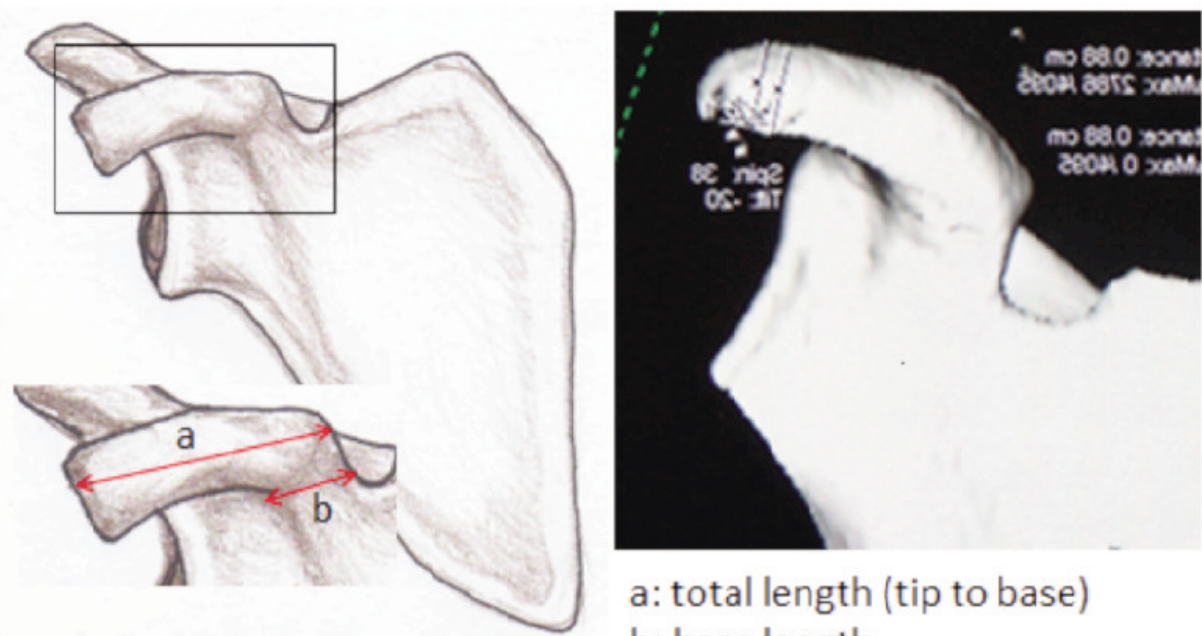

a: total length (tip to base)

b: base length

Fig. 1: Coronal view of coracoid process.
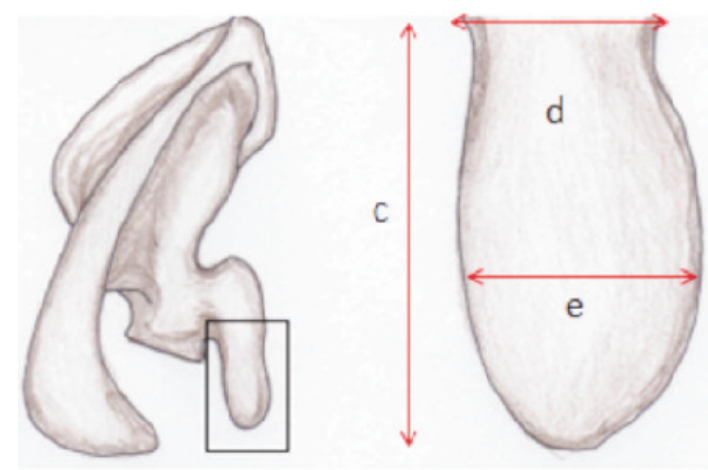

c: tip length (tip to midpoint)

d: midpoint width

e: tip width



Fig. 2: Axial view of coracoid process.

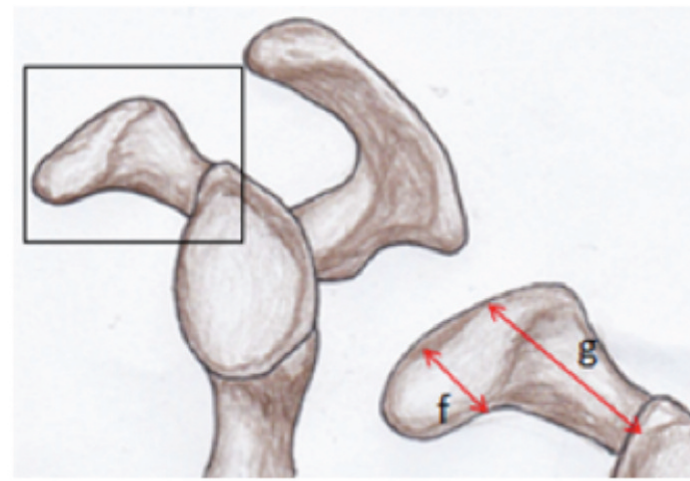

Fig. 3: Sagittal view of coracoid.

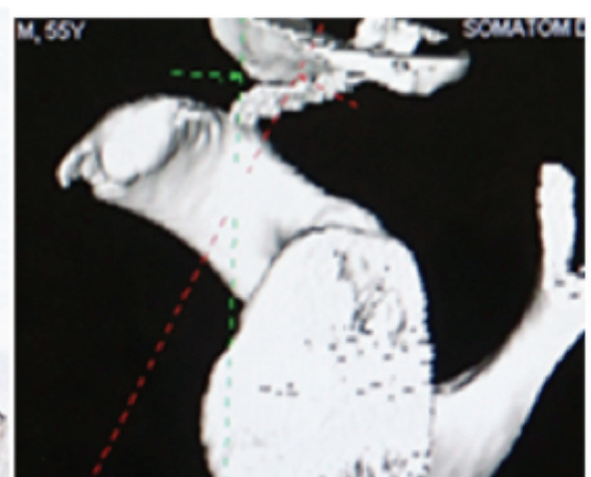

f: tip height

g: base height 
Rios et $a l^{3}$ described the anatomy of the coracoid base and clavicle from fresh cadavers and dry bone specimens as they studied in detail the anatomic origin of the $\mathrm{CC}$ ligaments on the distal clavicle. The mean length from the base of coracoid process to the tip was $45.2 \pm 4.1 \mathrm{~mm}$. The width and the height of the base of the coracoid were $24.9 \pm 2.4 \mathrm{~mm}$ and $11.9 \pm 1.8 \mathrm{~mm}$ respectively. The mean difference in the length of the coracoid process in males $(46.3 \pm 3.3 \mathrm{~mm})$ and females $(40.7 \pm 4.3 \mathrm{~mm})$ was $5.6 \mathrm{~mm}$. The width of the coracoid base was $25.4 \pm 2.0 \mathrm{~mm}$ in males and $23 \pm 2.8 \mathrm{~mm}$ in females and the height of the coracoid base was $12.2 . \pm 1.7 \mathrm{~mm}$ in males and $10.5 \pm 1.6 \mathrm{~mm}$ in female. There was no difference noted in the coracoid measurements when comparing the values between Caucasians and African-Americans.

Salzmann $e t a l^{2}$ studied the dimension and orientation of the $\mathrm{CC}$ footprints with respect to bony landmarks on coracoid. The measurements were obtained from fresh frozen cadaveric human shoulder. The length of the males and females coracoid was $46 \pm 1.9 \mathrm{~mm}$ and $42 \pm 1.4 \mathrm{~mm}$ respectively. The width of the base of coracoid was $16.7 \pm$ $2.9 \mathrm{~mm}$ in males and $13 \pm 1.7 \mathrm{~mm}$ in females while the height of the coracoid base was $15.4 \pm 1.3 \mathrm{~mm}$ in males and $13.6 \pm$ $1.7 \mathrm{~mm}$ in females. There was no significant ethnic difference in this study.

Dolan et $a l^{6}$ measured the tip of the coracoid process while studying its soft tissue attachments for coracoid transfer such as in Latarjet and Bristow procedures. The maximum length of coracoid transfer was $28.5 \pm 5.1 \mathrm{~mm}$, measured from the tip to the 'elbow' of the coracoid. The mean coracoid length was $45.6 \pm 4.2 \mathrm{~mm}$ while the mean coracoid tip width and height were $18.3 \pm 1.8 \mathrm{~mm}$ and $11.5 \pm 0.9 \mathrm{~mm}$ respectively. The midpoint of the coracoid was $22.8 \pm 2.1 \mathrm{~mm}$ from the base or tip. The mean of the midpoint width and height were $16.1 \pm 2.3 \mathrm{~mm}$ and $13.5 \pm 1.6 \mathrm{~mm}$ respectively.

The mean length of the tip of the coracoid process in the present study was $20.98+2.90 \mathrm{~mm}$. Male subjects had mean tip length of $22.06+3.09 \mathrm{~mm}$, while female subjects had $20.27+2.59 \mathrm{~mm}$. This means a minimum coracoid graft of $20 \mathrm{~mm}$ can be harvested for the coracoid transfer procedure in our population. Young et $a l^{7}$ suggested a coracoid graft greater than $25 \mathrm{~mm}$ can be used routinely in Latarjet procedure, while Dolan et $a l^{6}$ suggested the maximum of 28 $\mathrm{mm}(18.1+1.8 \mathrm{~mm}$ mean tip) of coracoid could be harvested for the same procedure.
There are few other studies measuring the coracoid process using CT scan. Armitage et $a l^{8}$ and Coale et $a l^{9}$ have conducted studies using CT scan on tip and base of coracoid process respectively. Their result showed significant larger coracoid process than we found in our study. Coale et al also found that $91.3 \%$ of the shoulders had medial cortical breach by creating a tunnel based on the anatomic footprints of the $\mathrm{CC}$ ligaments. However, if a transclavicular-transcoracoid tunnel was created a little further than the anatomic footprint, it resulted in mean remaining medial and lateral wall thickness before cortical breach of $7.3 \pm 1.7 \mathrm{~mm}$ and $7.0 \pm$ $1.6 \mathrm{~mm}$ respectively (coracoid base width of $28 \mathrm{~mm}$ ). The distance of this tunnel from the anatomic midpoint of CC ligament footprints was $9.9 \pm 2.2 \mathrm{~mm}$, resulting in nonanatomic CC ligaments reconstruction.

In theory, using a drill bit size of $5.0 \mathrm{~mm}$ to drill a coracoid tunnel in our sample (mean coracoid base length of $18.96 \mathrm{~mm}$ ) results in remaining wall thickness of $7 \mathrm{~mm}$ each side provided the tunnel is drilled in the central position. Given a tight window, eccentric tunnel preparation will increase the risk of cortical breach and coracoid fracture.

\section{LIMITATION OF STUDY}

Defining the dimensions of coracoid process in CT scan is a difficult task due to its tortuous shape ${ }^{8,9,11}$. The main challenge in this study is to identify the bony landmarks and portions of the coracoid process on the CT scan images. The 3D images have to be flipped and turned until they assumed the best position for measurement, as close to examining the native or cadaveric samples. Hence, it may not be accurate to compare this study and others. To reduce error in this study, the measurement was done by two independent observers. The sample size is also small, comparing the measurements in three different ethnic groups.

\section{CONCLUSION}

This study showed that the Malaysian population has smaller coracoid process. A maximum of $23 \mathrm{~mm}$ coracoid osteotomy can be safely used in coracoid transfer procedures. The findings also suggest that the incidence of coracoid fracture and implants pull-out following CC ligaments reconstruction surgery may be linked to the utilization of equipment and implants that are manufactured based on the Caucasian-sized coracoids. We recommend further study on biomechanics and effects of different drilling sizes used for CC ligaments reconstruction procedures to prove this hypothesis. 


\section{REFERENCES}

1. Bhatia DN, de Beer JF, du Toit DF. Coracoid process anatomy: implications in radiographic imaging and surgery. Clin Anat. 2007; 20: 774-84.

2. Salzmann GM, Paul J, Sandmann GH, Imhoff AB, Schottle PB. The coracoidal insertion of the coracoclavicular ligaments: an anatomic study. Am J Sports Med. 2008; 38: 1179-87.

3. Rios CG, Arciero RA, Mazzocca AD. Anatomy of the clavicle and coracoid process for reconstruction of the coracoclavicular ligaments. Am J Sports Med. 2007; 35: 811-7.

4. Gallino M, Santamaria E, Doro T. Anthropometry of the scapula: clinical and surgical considerations. J Shoulder Elbow Surg. 1998; 7: 284-91.

5. Lo IKY, Burkhart SS, Parten PM. Surgery about the coracoid: neurovascular structures at risk. Arthroscopy. 2004; 20: 591-5.

6. Dolan CM, Hariri S, Hart ND, McAdams TR. An anatomic study of the coracoid process as it relates to bone transfer procedures. J Shoulder Elbow Surg. 2011; 20: 497-501.

7. Young AA, Baba M, Neyton L, Godeneche A, Walch G. Coracoid graft dimensions after harvesting for the open Latarjet procedure. J Shoulder Elbow Surg. 2013; 22(4): 485-8.

8. Armitage MS, Elkinson I, Giles JW, Athwal GS. An anatomic, computed tomographic assessment of the coracoid process with special reference to the congruent arc Latarjet procedure. Arthroscopy. 2011; 27: 1485-9.

9. Coale RM, Hollister SJ, Dines JS, Allen AA, Bedi A. Anatomic considerations of transclavicular-transcoracoid drilling for clavicular ligament reconstruction. J Shoulder Elbow Surg. 2012; 22(1): 13-44.

10. Terra BB, Ejnisman B, de Figueiredo EA, Cohen C, Montero GC, Pochini AC, et al. Anatomic Study of the Coracoid Process: Safety Margin and Practical Implications. Arthroscopy. 2013; 29(1): 25-30.

11. Ljungquist KL, Butler RB, Griesser MJ, Bishop JY. Prediction of coracoid thickness using a glenoid width-based moder: implications for bone reconstruction procedures in chronic anterior shoulder instability. J Shoulder Elbow Surg. 2012; 21: 815-21. 